\section{Recent advances in accident and} emergency medicine

EDIToR,-We wish to draw to your attention the article recently published in the $B M F$ entitled "Recent advances in accident and emergency medicine". In the article Dr Stahmer advocates the use of serial measurement of creatine kinase $\mathrm{MB}$ isoenzyme to confirm acute myocardial infarction in patients with non-diagnostic electrocardiograms. Doing so she appears unaware of financial constraints operating here in the UK. The paper that Dr Stahmer bases this recommendation upon quotes a sensitivity to detect myocardial infarction in the first six hours, from the development of symptoms, of $95.7 \%$ with a specificity of up to $96 \%$. $^{2}$ The methodology involved venesection every 30-60 minutes for up to six hours.

Currently in our department we use creatine kinase measurements at presentation then at 2 and 4 hours. This follows work by Collinson and Stubbs who, using this method, showed an incremental change of $20 \%$ in creatine kinase between 0 and 4 hours to be $100 \%$ sensitive and $94 \%$ specific for patients with a degree of uncertainty in the diagnosis of acute myocardial infarction. ${ }^{3}$ An audit by next day follow up has shown a reduction in the rate of missed acute myocardial infarction from $6.7 \%$ to $<1 \%$. This method has obvious cost benefits over that advocated by $\mathrm{Dr}$ Stahmer as well as having strong implications regarding risk management. It may also be of interest, in light of one of the presentations at the British Association for Accident and Emergency Medicine conference in Birmingham, that we are soon to start a trial using point of care testing in conjunction with our practise outlined above.

P S MOSS Specialist Registrar, Accident and Emergency

R FREIJ

Consultant in Accident and Emergency, Mayday University Hospital, Mayday Road, Thornton Heath, Surrey CR7 7YE

1 Stahmer SA. Recent advances accident and emergency medicine. BMJ 1998;316:1071-4.

2 Puleo PR, Meyer D, Wathen C, et al. Use of rapid assay of subforms of creatine kinase $\mathrm{MB}$ to diagnose or rule out acute myocardial infarction. N Engl J Med 1994;331:561-6.

3 Collinson OP, Stubbs PJ. Early rule-in diagnosis of acute myocardial infarction $4 \mathrm{~h}$ post admission for rapid risk stratification by creatine kinases increment (creatine kinase change). Ann Clin Biochem 1996;33:308-13.

\section{A late presentation!}

EDITOR,-Last year I saw an $\mathbf{8 8}$ year old man who had fallen and had some "right scaphoid" tenderness. Radiographs of his right wrist showed an old un-united fracture of his scaphoid bone, but no new bony injury (see fig 1). He last fell in 1926, off his motorcycle, onto both hands. His right wrist had been sore ever since and it took him 71 years to present to a doctor.

Is this a record for a late presentation of an injury?

A FRASER-MOODIE

Consultant in Accident and Emergency, Emergency Department, Derbyshire Royal Infirmary NHS Trust, London Road, Derby DE1 $2 Q Y$

\section{Golf is a dangerous game}

EDITOR,-Golf related head injury in children is a significant problem in the West of Scotland, according to a three month prospective, observational study carried out between June and August 1997.

During this period, a record was kept of all children, aged 16 and under, presenting to the accident and emergency (A\&E) department of the Royal Alexandra Hospital in Paisley (catchment population 250000 ) with a golf related head injury. A concurrent record was kept of similar patients requiring admission to the regional neurosurgical centre at the Southern General Hospital in Glasgow (catchment population 2.7 million).

A total of 23 children attended the $A \& E$ department with such an injury, with a mean age of 8.0 years. All patients had sustained accidental injuries with 22 of these patients injured while observing another person playing golf. Only six of these were supervised by an adult and only three were playing golf on a recognised course at the time of injury. All patients were struck with either a club (20 cases) or a ball (three cases). The most common injury was scalp and facial lacerations, although one child sustained an acute extradural haematoma and another a compound depressed skull fracture. Both of these children were transferred to the regional neurosurgical centre.

Over the same period, 17 patients were admitted to the neurosurgical centre, with a mean age of 11.8 years. Of these, 13 patients sustained compound depressed skull fractures, all of whom required surgery, and two patients had acute extradural haematomas which needed emergency neurosurgical evacuation. A further two patients were admitted for computed tomography and observation only. There were no postoperative

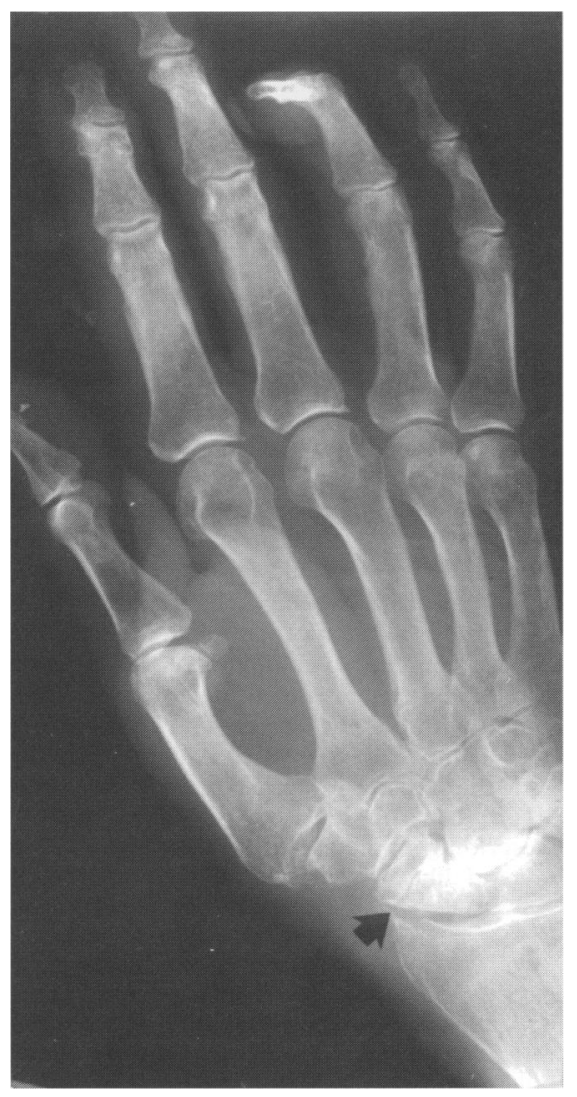

Figure 1 Radiograph of right wrist. complications and at two month follow up all the children had recovered fully.

Head injury is a major cause of morbidity in Western society and sport related incidents account for approximately $11 \%$ of all head injured patients attending $A \& E$ departments. ${ }^{1}$ Golf was shown to be one of the sports most commonly associated with head injury requiring referral to a regional neurosurgical centre. ${ }^{2}$ Interestingly, individuals injured at play and not on a recognised golf course were excluded from this study, although golf related head injuries remained the largest single group, with 14 admissions over a five year period. The complications related to compound depressed skull fractures and intracranial haematoma are well documented. ${ }^{3}$

The majority of children in this study were injured at play in an unsupervised setting while observing someone else playing golf. Serious head injuries are being sustained. Children require education and supervision if this is to be avoided.

ADAM CRAWFORD MCGUFFIE Specialist Registrar in Accident and Emergency

MICHAEL OWEN FITZPATRICK Specialist Registrar in Neurosurgery, Southern General NHS Trust, 1345 Govan Road, Glasgow G51 4TF

DAVID HALL

Staff Grade in Accident and Emergency, Royal Alexandra Hospital, Corsebar Road, Paisley PA2 9PN

1 Strang I, McMillan R, Jennett B. Head injuries in accident and emergency departments at Scottish hospitals. Injury 1978;10:154-9.

2 Lindsay KW, McLatchie G, Jennett B. Serious head injury in sport. BMJ 1980;281:789-90.

3 Teasdale GM. Head injury. J Neurol Neurosurg Psychiatry 1995;58:526-39.

Fatal intra-abdominal injury associated with incorrect use of a seat belt

EDITOR,-A 64 year old woman was the seat belted front seat passenger of a vehicle involved in a high speed front end collision road traffic accident. The woman was transported by paramedic crew to our accident and emergency department. On arrival she was fully conscious (Glasgow coma score 15/15) and talking. She was obese and pale and her abdomen was bruised in the line of her seat belt.

Standard resuscitation was performed along Advanced Trauma Life Support (ATLS) principles but she became progressively haemodynamically unstable and was transferred to the operating theatre for an emergency laparotomy where a small splenic laceration was found. The patient died during the procedure from uncontrollable massive retroperitoneal haemorrhage.

Seat belts, when correctly applied, are effective in minimising injury but they do have the potential to cause serious abdominal injury which, when fatal, is usually the result of intra-abdominal haemorrhage. ${ }^{12}$ It is clearly emphasised in the ATLS providers' manual that the lap strap should be positioned between the anterior superior iliac spines and the thighs. ${ }^{3}$ However, while seat belt compliance appears to have improved among the general public, both through health education and legislation, there appears to be little emphasis on the importance of using these devices correctly.

In the case described above, the lap strap lay across the abdomen and the diagonal strap above both breasts, the two meeting at the 